\title{
Valuing Arts-based Academic Projects in a Faculty of Nursing: Experiences of Graduate Students and Supervisors
}

\author{
Susan E. Slaughter \\ Faculty of Nursing, University of Alberta, susan.slaughter@ualberta.ca \\ Mandy M. Archibald \\ University of Adelaide, mma@ualberta.ca \\ Lauren Albrecht \\ University of Alberta, lauren.albrecht@ualberta.ca \\ Bryan Say \\ Dufferin Place, Bryan.Say@viha.ca \\ Pauline Paul \\ University of Alberta, ppaul@ualberta.ca \\ Shannon D. Scott \\ University of Alberta, ss14@ualberta.ca
}

Follow this and additional works at: https://qane-afi.casn.ca/journal

Part of the Fine Arts Commons, Graphic Design Commons, Illustration Commons, Medical Humanities Commons, and the Nursing Commons

\section{Recommended Citation}

Slaughter, Susan E.; Archibald, Mandy M.; Albrecht, Lauren; Say, Bryan; Paul, Pauline; and Scott, Shannon D. (2018) "Valuing Arts-based Academic Projects in a Faculty of Nursing: Experiences of Graduate Students and Supervisors," Quality Advancement in Nursing Education - Avancées en formation infirmière: Vol. 4: Iss. 1, Article 6.

DOI: https://doi.org/10.17483/2368-6669.1126

This Article is brought to you for free and open access by Quality Advancement in Nursing Education - Avancées en formation infirmière. It has been accepted for inclusion in Quality Advancement in Nursing Education - Avancées en formation infirmière by an authorized editor of Quality Advancement in Nursing Education - Avancées en formation infirmière. 


\section{Introduction}

The purpose of this article is to explore student and supervisor experiences and perspectives regarding the advantages and challenges of arts-based academic projects in the context of Canadian graduate nursing education programs. Arts-based research is the use of any art form during any aspect of the research process including generating, interpreting, or communicating knowledge (Knowles \& Cole, 2008). We define arts-based academic projects as graduate-level projects that incorporate a significant artistic component and that culminate in a final report of a capping exercise, a thesis, or a dissertation. In this article, we summarize key features of arts-based research and arts-based academic projects, describe the work and experience of three graduate students and their supervisors with arts-based academic projects (including their perceptions of the advantages and challenges encountered in the process of completing these projects), and discuss implications of these experiences for future arts-based projects that may be conducted in schools or faculties of nursing.

\section{Background}

For centuries Western thought has focused on the differences between arts and sciences, which has contributed to separating these ways of knowing (Eisner \& Powell, 2002). However, more recently the borders between art and science have been conceptualized as "malleable" and "porous" (Barone \& Eisner, 2012, p. 7). The dichotomy of art and science is rejected by those who assert that when science is well done, aesthetic or artistic features of scientists' activities are recognizable, such as imagination, somatic knowledge, empathic knowledge, nest building, and sociocultural motivators to pursue knowledge (Barone \& Eisner, 2012; Eisner \& Powell, 2002). Barone and Eisner argue that science "can be lifted to an artistic plane when the work is imaginative, sensitive to nuance, expressive in character, and satisfying or moving to experience" (p. 46). According to Barone and Eisner (2012), arts-based research is a broad approach to social inquiry that is intended to destabilize or question prevailing, conventional points of view and see the world in new ways through fresh eyes or alternative perspectives. Rather than viewing research as employing the scientific method, Barone and Eisner (2012) view research in the broadest sense of returning again and again in order to shed light on some phenomena of interest. Their conception of arts-based research is the theoretical foundation for this article.

Just as Barone and Eisner observe that arts-based research has both inquiry and representational phases, two systematic reviews of arts-based health research concluded that artsbased research serves two main purposes: (a) the production or generation of knowledge; and (b) the translation or dissemination of research findings (Boydell, Gladstone, Volpe, Allemang, \& Stasiulis, 2012; Fraser \& al Sayah, 2011). Data generation using arts-based methods permits deeper probing into research questions and empowers research participants to reflect and express themselves more deeply than the traditional qualitative interview-based methods (Boydell et al., 2012). The translation of health research findings is defined in the Canadian context as a "dynamic and iterative process that includes synthesis, dissemination, exchange and ethically sound application of knowledge to improve the health of Canadians, provide more effective health services and products and strengthen the health care system" (Canadian Institutes of Health Research, 2016). Arts-based methods to translate health research findings have made research more accessible, and more accessible to a broader audience, compared with academic text-based methods (Bartlett, 2013; Boydell et al., 2012). Arts-based knowledge translation has the potential to make complex ideas accessible that otherwise would be difficult to convey with 
words (Archibald, Caine, \& Scott, 2014; Colantonio et al., 2008; Frank, 2004; Rieger \& Schultz, 2014). There is a powerful emotive potential of arts-based knowledge translation that can engage audiences both emotionally and cognitively (Archibald, Caine, \& Scott, 2017; Camic, 2008; Colantonio et al., 2008; Rieger et al., 2014). Comics, for example, can provide comic relief from otherwise serious or sensitive topics (Bartlett, 2013).

Over the past several decades, arts-based academic projects have been conducted in education and health academies (Camic, 2008; Frei, Alvarez, \& Alexander, 2010). For example, scholars in the Faculty of Education at one Canadian university $s$ examined a decade of production of arts-based dissertations. They found there is no one way to do arts-based educational research; the dissertation projects took varied forms including exhibitions of visual art, performances of drama, and publications of literary art. The dissertations demonstrated a commitment to the aesthetic, to innovation in inquiry, to deeper understanding, and to a search for meaning (Sinner, Leggo, Irwin, Gouzouasis, \& Grauer, 2006).

Arts-based research is relatively established in the field of education; however, we agree with Bruce et al. (2013) that the potential of creative platforms for nursing research has not been sufficiently recognized. Helping graduate nursing students, who are artistically inclined, to find a relationship between the arts and nursing research can be an important motivator for advanced education. Supervisors and committee members play a key role in fostering the creativity of students, building on their strengths, and encouraging them to pursue innovative theses or capping exercises (Whitelock, Faulkner, \& Miell, 2008). Similarly, graduate program coordinators and associate deans of graduate programs can support these students by encouraging and approving projects that are less conventional.

In this paper, the arts-based academic projects of three graduate nursing students are described along with the perceptions of the students and their supervisors related to these projects. In the process of planning this paper, three tenured faculty members from a Canadian Faculty of Nursing met face-to-face on three occasions. From September to December 2015, we discussed the advantages and challenges that we experienced in supervising our students. Notes taken during these planning meetings were collated and summarized. In October 2015, the three supervisors asked three of their graduate students who were engaged in arts-based academic projects to join us as co-authors by summarizing their projects in a paragraph or two, reflecting upon their experiences in conducting their projects, and then recording the advantages and challenges that they encountered along the way. These student contributions were slightly modified to enhance the flow of the paper. For example, one student submitted ideas in point form. Care was taken to preserve the voice of the students by reporting all of their ideas using their words as much as possible. Summaries of three students' academic projects and their reflections are summarized below.

\section{Master's Student Capping Project}

In my capping project I explored how comics can be used as a medium to disseminate qualitative research findings. Working with secondary data, transcripts from semi-structured research interviews with health care aides, I identified health care aides' notable descriptions of resident "success stories": positive outcomes of a mobility intervention. Then I interpreted these excerpts using an electronic pen and the Bitstrips Program (Bitstrips Corporation, Toronto, Canada) to create eight comics. I adapted the style, length, and aesthetic of each comic to correspond to each research transcript excerpt. Each comic was independent of the others, yet 
consistent characters appeared in multiple comic strips. Employing artistic freedom, I developed the comic characters to be generic and unassuming, yet portraying older adults who reflect diverse family structures, cultures, and body types. The result was a literary and artistic world where diversity and idealistic values for older adults were embraced.

It was fulfilling for me to create a connection between the reader, the comic characters, and content all in the spirit of fostering engagement. I was excited to produce a comic that could be both useful and enjoyable. This capping exercise also encouraged me to reflect on research dissemination. At times, it was difficult to interpret and apply the comic medium in my project. Although a professional cartoonist may have improved the style and creation of each comic, a professional cartoonist would not have understood the care context in the way that I do. Since I worked with secondary data, interview transcripts, the comics were created without the benefit of knowing the body language or tone of the research participants. The setting, characters, and scenarios from the transcripts were abbreviated to fit within a comic format; however, abridging the text introduced the risk of changing the intent of the research participants.

\section{Doctoral Student Dissertation 1}

Visual art and storytelling have untapped potential as vehicles to deliver asthma education to parents in an engaging and comprehensible manner that is based on contemporary, high-quality evidence and reflects parents' experiences with their child's asthma. I conducted an interpretive descriptive qualitative study and used these data to inform the development of visual art and story-based digital educational tools for parents of children with asthma (Archibald, Hartling, Ali, Caine, \& Scott, 2017). Working closely with a creative consulting team (i.e., an illustrator, a creative writer, and a design media company) and consulting with an expert advisory committee (i.e., experts in child health, knowledge translation, and emergency medicine), we created a 28-page digital storybook. Designed as an asthma diary, each diary entry reflects the experiences, concerns, and hopes of a mother of a young child with asthma. The story reveals critical milestones, such as the initial onset of symptoms, receiving a diagnosis, and seeking emergency care. Information about asthma is embedded within the story and additional information can be accessed through icons in the book. I then completed usability testing following my dissertation (Archibald \& Scott, 2016).

I challenged and was challenged by mainstream conceptualizations of evidence. While some colleagues regarded arts-based research with skepticism, others regarded my work as a powerful approach to engage stakeholders in research while concomitantly initiating debate of the political and philosophical tenants of evidence. I experienced tension between the emotive and humanistic potential of arts-based research and the need to be authentic and staying true to the data. I had to decide what to exclude and what to include. I had to balance the actual experience of asthma with ideal approaches to management. Furthermore, publishing this type of research can be challenging given the restrictions in publication guidelines, such as file size and use of color.

Little empirical evidence exists about how to ideally create knowledge translation tools and to what effect. The underdeveloped nature presents both challenge and opportunity: one must read broadly to acquire theoretical traction for one's research, yet there is a great opportunity to contribute and shape the knowledge base in the field. 


\section{Doctoral Student Dissertation 2}

For my dissertation, I am evaluating the effectiveness of an arts-based, digital knowledge whiteboard animation video for parents of children with acute gastroenteritis. The video content was informed by a qualitative, descriptive study of parents $(n=15)$ of children with vomiting and diarrhea seeking care in the emergency department (Albrecht, Hartling, \& Scott, 2017). The whiteboard animation video is designed to provide key information in a short period of time. To capitalize on this feature we developed a short, impactful storyline from the qualitative findings that focused on parents' decisions to take their child to the emergency department. We contracted a variety of artists (i.e., a writer, an animator, and a voice actor) to develop and refine the arts-based components with guidance from the research team. To ensure the whiteboard animation video resonated with our key audience, we engaged parents and emergency clinicians in a feedback process on the structure, aesthetics, and content of the video before it was finalized. I also assessed the parents' usability of the video on a digital platform with a survey and focus groups. The video demonstrated positive results across usability domains and the focus groups provided context about how and where parents could access this tool for maximum benefit. The next step is to determine the effectiveness of the whiteboard video with parents making health care decisions for a child with acute gastroenteritis.

There is little guidance on how to engage artists in the development process. For instance, it was challenging to communicate the synthesized evidence on treatment and management of acute gastroenteritis to the artists to enable them to develop the composite narrative or art. I had to learn the expectations of the artist, and they had to teach me about their creative process. Acting upon the feedback from stakeholders was not straightforward. Sometimes it was difficult to turn some critical feedback into a workable solution. For example, some parents wanted to receive information as quickly as possible, which would mean eliminating narrative or artistic elements in favour of a checklist. Clinicians wanted to use generic drug names rather than brand names; however, this would conflict with parents' needing to quickly locate important information.

\section{Advantages and Challenges Encountered by the Supervisors}

The three supervisors of the students believe that focusing on students' strengths is a powerful tool that can facilitate learning. These beliefs are congruent with the principles of strengths-based education and strengths-based advising (Lopez \& Louis, 2009; Schreiner \& Anderson, 2005). In this approach to learning, teaching, and advising in higher education, part of the role of educators is to help students discover their strengths and use these to enhance their learning. In our early encounters with the graduate students who have contributed to this paper, we discovered they all had artistic talents, or an affinity to art, that could be applied in the context of their graduate projects.

With arts-based knowledge translation of research findings forming the basis of these academic projects, the supervisors identified an opportunity for multiphase research training. For example, research projects could include a preliminary phase of gathering the evidence-based content for dissemination (e.g., knowledge synthesis or primary data collection), followed by developing an intervention package/tool (e.g., arts-based project), disseminating the arts-based project/tool, and finally evaluating it. Multiple phases were included in the structure of both dissertation project exemplars. 
We were concerned about how arts-based academic projects are viewed by faculty members. Accordingly, we considered the role of the graduate studies office in encouraging and supporting arts-based projects. Specifically, we questioned how these types of academic projects could be discussed as viable options for graduate nursing research. We offered that strategic communication coming from the graduate studies office would validate the option to conduct an arts-based academic project and might alleviate some of the perceived or perhaps authentic negativity that some of us have experienced from our colleagues. Specifically, one supervisor shared how some of her colleagues implicitly questioned the rigour of an arts-based project for graduate education. In response to what nursing colleagues thought and said about arts-based research projects and programs of research, we discussed how we had to develop "thick skins". We had received back-handed comments from colleagues who did not appreciate the potential of arts-based academic projects to contribute to the development of the discipline with academic rigor. We wondered about how we could best support our students to experience intellectual safety as they were also likely to encounter similar negative comments and devaluing of their academic projects.

We shared uncertainty about how to supervise our students in this new territory of artsbased academic projects. For example, we described our struggles with how to advise our students to report and discuss their arts-based findings and how to evaluate their final academic product. One supervisor highlighted how she attempted to mitigate some of this uncertainty by embedding the arts-based project within a broader, more conventional, multiphase research project. She reflected that she thought this approach addressed some of her colleagues' skepticism of this type of research.

Reporting and disseminating arts-based projects introduced unique challenges for us as supervisors. Our learners often struggled to integrate the actual arts-based component into their theses and dissertation products. We identified challenges with submitting manuscripts to standard peer-reviewed journals. Normally journals limit the number of graphics that may be included in a manuscript, and the color of graphics can be prohibitively expensive when publishing in journals that are not online.

Intellectual property can become a muddy, yet highly educational issue, with arts-based academic projects involving contracted artists. Questions that we had to navigate with learners pertained to copyright issues: is it the student, the contracted artist, or the supervisor who has copyright? Furthermore, we had to navigate how the product of the arts-based project is copyright protected when the academic project involved internet-based knowledge translation interventions such as digital storybooks and animation videos for parents and children.

\section{Discussion}

The exemplars of specific arts-based academic projects provided the framework for an exploration of student and supervisor perspectives of these relatively novel health research products. We probed the opportunities and challenges that we encountered in the context of a faculty of nursing where there is significant strength in faculty members' research programs, which span qualitative, quantitative, and mixed methods research.

The Canadian Association Schools of Nursing (CASN) has developed a National Nursing Education Framework which articulates the core expectations for undergraduate and graduate nursing programs (CASN, 2015). The expectations for each type of program are organized into six domains, each of which has a guiding principle and several essential components. The 
guiding principle of the "research, methodologies, critical inquiry \& evidence" domain for the master's program, is to foster "the ability to contribute to nursing knowledge through systematic inquiry, knowledge development, translation and scholarship" (p. 12). In the capping project exemplar described in this article, the student's knowledge translation work drew upon his supervisor's research data to create a product (a series of comics) that could be used for the novel and engaging dissemination of the research findings. In contrast to more substantial expectations for the doctoral students' dissertations, the expectations for this master's student's capping exercise were circumscribed. He was not expected to develop new knowledge and create a dissemination product. Instead he engaged with existing research interview transcripts to focus on creating comics, and discussed his work in relation to the relevant literature.

At the doctoral level, the "communication \& collaboration" domain of the National Nursing Education Framework includes the essential components "ability to disseminate complex knowledge to a variety of diverse audiences" (p. 15) and "creation of innovative strategies for knowledge, dissemination and mobilization to inform the discipline and practice of nursing" (p. 15). The two doctoral student exemplars described in this paper generated new knowledge and created innovative strategies to disseminate their findings by using arts-based approaches. All three graduate student exemplars demonstrate how arts-based academic projects can contribute to meeting the expectations of Canadian nursing education programs outlined in the National Nursing Education Framework.

Two scoping reviews of arts-based health research identified performance art as more commonly used for knowledge translation purposes, while literary and visual art as more commonly used for knowledge production (Boydell et al., 2012; Fraser \& al Sayah, 2011). As it happens, three of the students we were supervising at the time of writing this paper integrated visual art into scholarly projects grounded in the principles of knowledge translation. Visual art is defined as "an artistic subset inclusive of those art forms amenable to visual perception, such as painting, drawing or sculpture" (Archibald, Scott, \& Hartling, 2014, p. 5). Our students' use of visual arts-based approaches for the dissemination of research findings, rather than the production of research, may be due to the fact that visual arts are a more common method in health research than performance or literary arts (Fraser \& al Sayah, 2011). Alternatively, our students' focus on dissemination of research findings using arts-based approaches may be due to the strong presence of several knowledge translation research programs in our faculty of nursing.

Others have focused their discussion on the challenges of conducting arts-based research (Atkins, 2013; Forinash, 2016; Smith, 2012). The ability to move between full engagement in artistic experiences and in the "sphere of more linear thinking" is challenging, but necessary for arts-based research. There is ambiguity and uncertainty when juxtaposing the artistic process and the research process (Forinash, 2016). Based on our findings, we suggest that similar challenges are encountered when using the arts in the context of knowledge translation. There has been limited use of arts-based knowledge translation in nursing faculties (Archibald et al., 2017; Bruce et al., 2013; Rieger \& Schultz, 2013).

As supervisors, we acknowledged our uncertainty with how to evaluate our students' final academic arts-based projects. Other researchers have grappled with the challenge of assessing arts-based works in the absence of assessment guidelines. In an academic setting, divergence from traditional dissertations has the potential to lead to supervisors' challenges with evaluating the results of an arts-based academic project (Butler-Kisber, 2002; Forinash, 2016). Forinash (2016) advises balancing traditional standards and criteria with flexibility. For example, 
flexibility is required when the final presentation format for an arts-based research project may not align with traditional formats such as a five-chapter thesis (Atkins, 2013). Suggested criteria judge the qualities of arts-based research more generally. For example, Barone and Eisner (2012) recommended criteria including incisiveness (getting to the heart of the question), concision (being concise or distilling to the essence), coherence (making sense), generativity (promoting understanding and action), social significance (importance for the larger community), and evocation and illumination (feeling and grasping the meanings). Specific to arts-based knowledge translation, Rieger and Schultz (2014) proposed four evaluative tenants: facilitation of an iterative approach with audience members, incorporation of meaningful aesthetic qualities, engagement of audience members through the contextual representation of research findings, and encouragement of diverse audiences to access and reflect on research outputs. Application of agreed-upon evaluative standards could contribute to the trustworthiness and legitimacy of the arts-based academic project.

One graduate student's reflection identified the need to ensure congruence between her research data and the arts-based knowledge translation product. Her concern about "staying true to the data" is not unique and is one discussed by Lafrenière and Cox (2013). They developed a three-component meta-framework to assess the quality and effectiveness of disseminating health research findings using the arts. Their framework includes "normative criteria" which focus on the quality of the research data and data analysis, "substantive criteria" which relate to the technical or artistic aspects of the work, and "performative criteria" which pertain to the effect of the final product on the audience. Lafrenière and Cox pay homage to the foundational importance of the arts-based product being representative of the research participants' voice through stressing that this aspect is a sine qua non for determining the quality of an arts-based work.

As the creator of comics to disseminate research findings, the master's student noted he was at an advantage over a professional cartoonist with his understanding of the care context. Lafrenière and Cox (2013) assert that unless artistic skill can be demonstrated, a researcher should partner with a qualified artist to create an arts-based work. The two doctoral students spoke of the potential challenge of working with a consultant artist when there is a dispute about how the artist represents or interprets the student's data. Bartlett (2013) made this same observation. Understanding who owns the intellectual property rights of arts-based academic project outputs can become complicated when the evidence-based findings of the student intersect with the artistic contributions of a consultant artist. Questions arising from projects such as this include: does the project belong to the student who generated the evidence, to the artist who created the artistic components to support translation of the evidence, or to the supervisor whose program of research inspired and supported the research? In cases such as this, it is necessary to openly discuss intellectual property rights (Bruce et al., 2013). Researcher Boydell (2011) described her experience of developing a contract with an artist to clarify the intellectual property rights of the artistic product which integrated her research findings.

As the two doctoral students reflected on their projects, they expressed concern about "What counts as evidence?" and whether their arts-based projects, which incorporated qualitative research findings, would be respected as evidence to guide nursing practice. The nature of evidence has been discussed in the nursing philosophical literature for many years (Romyn, et al., 2003; Rycroft-Malone, et al., 2004). A broad evidence base is advocated by nursing scholars, variously conceptualized to include research, clinical experience, patient experience, and local 
context (Rycroft-Malone et al., 2004), as well as knowledge derived from historic or scientific evaluation (Romyn et al., 2003). This broad evidence base includes findings derived from qualitative research which are considered to be an essential component of evidence available to guide nursing practice (Morse, 1999).

In our experience, colleagues do not always understand the nature and contribution of arts-based approaches. As supervisors and students, we experienced issues of intellectual safety as we pushed the boundaries of what constitutes an academic graduate project. We are not alone; others have reported challenges and resistance that come with supervising graduate students' arts-based projects. Sinner et al. (2006) noted how the validity of arts-based research approaches may still be questioned in some circles, Atkins (2013) revealed how she and her graduate students had to explain and justify their use of arts-based research to suspicious colleagues, and Moon (2013) described his experience of artistic modes of inquiry being dismissed by art therapy educators and researchers. In advocating for arts-based health research as a scholarly activity worthy of recognition, Boydell et al. (2016) explored aspects of academic legitimacy that debated structure versus flexibility in the research process, truth and accuracy in the representations of research in art, and traditional versus innovative academic contributions and impacts. They commented that in health research the biomedical model and traditional positivist empiricism make it difficult to receive recognition for arts-based research, which draws upon a constructivist philosophy.

It may be that working in familiar territory with predictable outcomes from established post-positivist research approaches is the path of least resistance and the way to remain safe from criticism. We posit that the risk associated with pursuing arts-based projects is worth the (minimal) intellectual safety concerns that we have encountered. Sinner et al. (2006) identified the importance of creating a network of academic colleagues that value arts-based approaches and can contribute to their refinement. We concur. Champions are needed to support students venturing into these less traditional research approaches. Faculty members, including graduate program coordinators and associate deans of graduate programs, can help others to understand the value of these arts-based academic projects.

\section{Limitations}

We sampled our current or recently graduated nursing students, from a single Canadian Faculty ofNursing, to inform this discussion. The sample of students was small and their academic projects only involved visual art. As such, the transferability and generalizability of our experience and perspectives to other Faculties, and to other types of art may be limited. Nevertheless, our experience appears to resonate with other reports in the literature.

\section{Conclusion}

In this paper, we have explored student and supervisor perceptions of arts-based academic projects within a Faculty of Nursing. Drawing upon the work of three graduate students' arts-based academic projects, we have described the advantages and challenges associated with this relatively new approach to scholarship. We acknowledge that graduate work in this space opens up the possibility to learn from other Faculties (e.g., arts or education) that have a longer tradition of arts-based academic projects. Further dialogue is needed in Nursing on the use of a range of arts-based approaches in academic projects. We invite others to expand the discussion. 


\section{References}

Albrecht, L., Hartling, L., \& Scott, S. D. (2017). Pediatric acute gastroenteritis: Understanding caregivers' experiences and information needs. Canadian Journal of Emergency Medicine. 19(3), 198-206. https://doi.org/10.1017/cem.2016.363

Archibald, M. M., \& Scott, S. (2017). Communicating through eBooks: Usability testing of a digital, arts-based knowledge translation tool for parents of children with asthma. Manuscript submitted for publication.

Archibald, M. M., Hartling L., Ali, S., Caine, V., \& Scott, S. (2016). Developing "My Asthma Diary": A process exemplar of a Patient-Driven Arts-Based Knowledge Translation Tool. Manuscript submitted for publication.

Archibald, M. M., Caine, V., \& Scott, S.D. (2014). The development of a classification schema for arts-based approaches to knowledge translation. Worldviews on Evidence Based Nursing, 11(5), 316-324. https://doi.org/10.1111/wvn.12053

Archibald, M.M., Caine, V., \& Scott, S.D. (2017). Intersections of the arts and nursing knowledge. 24(2), e12153. https://doi.org/10.1111/nin.12153

Archibald, M., Scott, S., \& Hartling, L. (2014). Mapping the waters: A scoping review of the use of visual arts in pediatric populations with health conditions. Arts and Health, 6(1), 5-23. https://doi.org/10.1080/17533015.2012.759980

Atkins, S. (2013). Where are the five chapters? Challenges and opportunities in mentoring students with arts-based dissertations. In S. McNiff (Ed.), Art as research: Opportunities and challenges (pp. 57-64). Chicago, IL: Intellect.

Bartlett, R. (2013). Playing with meaning: using cartoons to disseminate research findings. Qualitative Research, 13(2), 214-227. https://doi.org/10.1177/1468794112451037

Barone, T., \& Eisner, E. W. (2012). Arts-based research. Los Angeles, CA: Sage.

Boydell, K. M. (2011). Making sense of collective events; The co-creation of a research-based dance. Forum: Qualitative Social Research, 12(1), 1-20. Retrieved from http://www.qualitative-research.net/index.php/fqs/article/viewArticle/1525/3143

Boydell, K. M., Gladstone, B. M., Volpe, T., Allemang, B., \& Stasiulis, E. (2012). The production and dissemination of knowledge: A scoping review of arts-based health research. Forum: Qualitative Social Research, 13(1), 1-24. http://nbnresolving.de/urn:nbn:de:0114-fqs1201327

Boydell, K. M., Hodgins, M., Gladstone, B. M., Stasiulis, E., Belliveau, G., Cheu, H., ... Parsons, J. (2016). Arts-based health research and academic legitimacy: transcending hegemonic conventions. Qualitative Research, 16(6), 681-700. https://doi.org/10.1177/1468794116630040

Bruce, A., Schick-Makaroff, K. I., Sheilds, L., Beuthin, R., Molzahn, A., \& Shermak, S., (2013). Lessons learned about art-based approaches for disseminating knowledge. Nurse Researcher, 21(1), 23-28. https://doi.org/10.7748/nr2013.09.21.1.23.e356 
Butler-Kisber, L. (2002). Artful portrayals in qualitative inquiry: The road to found poetry and beyond. Alberta Journal of Educational Research, 48(3), 229-239. Retrieved from http://ajer.journalhosting.ucalgary.ca/index.php/ajer/article/view/328

Canadian Association of Schools of Nursing [CASN]. (2015). National Nursing Education Framework. Ottawa, ON: Author.

Canadian Institutes of Health Research. (2016). Knowledge translation. Retrieved from http://www.cihr-irsc.gc.ca/e/29418.html

Camic, P. M. (2008). Playing in the mud: Health psychology, the arts and creative approaches to health care. Journal of Health Psychology, 13(2), 287-298. https://doi.org/10.1177/1359105307086698

Colantonio, A., Kontos, P. C., Gilbert, J. E., Rossiter, K., Gray, J., \& Keightley, M. L. (2008). After the crash: Research-based theatre for knowledge transfer. Journal of Continuing Education in the Health Professions, 28(3), 180-185. https://doi.org/10.1002/chp.177

Eisner, E., \& Powell, K. (2002). Special series on arts-based educational research. Curriculum Inquiry, 32(2), 131-159. https://doi.org/10.1111/1467-873x.00219

Forinash, M. (2016). On supervising arts-based research. Music Therapy Perspectives, 34(1), 41-45. https://doi.org/10.1093/mtp/miv048

Frank, A. W. (2004). The renewal of generosity: Medicine, illness and how to live. Chicago, IL: University of Chicago Press.

Fraser, K. D., \& al Sayah, F. (2011). Art-based methods in health research: A systematic review of the literature. Arts \& Health, 3(2), 110-145. https://doi.org/10.1080/17533015.2011.561357

Frei, J., Alvarez, S., \& Alexander, M. (2010). Ways of seeing: Using the visual arts in nursing education. Journal of Nursing Education, 49(12), 672-676. https://doi.org/10.3928/01484834-20100831-04

Knowles, J. G., \& Cole, A. L. (2008). Handbook of the arts in qualitative research: Perspectives, methodologies, exemplars, and issues. Thousand Oakes, CA: Sage Publishing.

Lafrenière, D., \& Cox, S. M. (2013). 'If you can call it a poem': Toward a framework for the assessment of arts-based works. Qualitative Research, 13(3), 318-336. https://doi.org/10.1177/1468794112446104

Lopez, S. J., \& Louis, M. C. (2009). The principles of strengths-based education. Journal of College and Character, 10(4), 1-8. https://doi.org/10.2202/1940-1639.1041

Moon, B. L. (2013). Mentoring and other challenges in art-based enquiry: You will figure it out. In S. McNiff (Ed.), Art as research: Opportunities and challenges (pp. 31-38). Chicago, IL: Intellect.

Morse, J. M. (1999). Qualitative generalizability. Qualitative Health Research, 9, 5-6. https://doi.org/10.1177/104973299129121622

Rieger, K., \& Schultz, A. S. H. (2014). Exploring arts-based knowledge translation: Sharing research findings through performing the patterns, rehearsing the results, staging the 
synthesis. Worldviews on Evidence-Based Nursing, 11(2), 133-139.

https://doi.org/10.1111/wvn.12031

Romyn, D. M., Allen, M. N., Boschma, G., Duncan, S. M., Edgecombe, N., Jensen, L.A., ... Warnock, F. (2003). The notion of evidence in evidence-based practice by the nursing philosophy working group. Journal of Professional Nursing, 19(4), 184-188. https://doi.org/10.1016/s8755-7223(03)00087-5

Rycroft-Malone, J., Seers, K., Titchen, A., Harvey, G., Kitson, A., \& McCormack, B. (2004). What counts as evidence in evidence-based practice? Journal of Advanced Nursing, 47(1), 81-90. https://doi.org/10.1111/j.1365-2648.2004.03068.x

Schreiner, L. A., \& Anderson, E. (2005). Strengths-based advising. NACADA Journal, 25(2), 20-28. https://doi.org/10.12930/0271-9517-25.2.20

Sinner, A., Leggo, C., Irwin, R. L., Gouzouasis, P., \& Grauer, K. (2006). Arts-based educational research dissertations: Reviewing the practices of new scholars. Canadian Journal of Education, 29(4), 1223-1270. https://doi.org/10.2307/20054216

Smith, T. D. (2012). Shall I hide an arts-based study within a recognized qualitative framework? Negotiating the spaces between research traditions at a research university. In S. McNiff (Ed.), Art as research: Opportunities and challenges (pp. 191-200). Chicago, IL: Intellect.

Whitelock, D., Faulkner, D., \& Miell, D. (2008). Promoting creativity in PhD supervision: Tensions and dilemmas. Thinking Skills and Creativity, 3, 143-153. https://doi.org/10.1016/j.tsc.2008.04.001 